\title{
Caplet Dosage Form
}

National Cancer Institute

\section{Source}

National Cancer Institute. Caplet Dosage Form. NCI Thesaurus. Code C97197.

A solid dosage form in which a tablet has been compacted into capsule shape. 